\title{
Teoria da localização, teoria da renda fundiária urbana e o processo da obsolescência espacial urbana
}

Theory of location, theory of urban ground rent and the process of urban spatial obsolescence

Théorie de l'emplacement, théorie de la rente foncière et le processus

d'obsolescence spatiale urbaine

Teoría de la localización, teoría de la renta de la tierra urbana y el proceso de la obsolescencia espacial urbana

\section{André Vinicius Martinez Gonçalves}

\section{(2) OpenEdition}

Journals

Edição electrónica

URL: http://journals.openedition.org/espacoeconomia/4095

DOI: $10.4000 /$ espacoeconomia.4095

ISSN: 2317-7837

Editora

Núcleo de Pesquisa Espaço \& Economia

Refêrencia eletrónica

André Vinicius Martinez Gonçalves, «Teoria da localização, teoria da renda fundiária urbana e o processo da obsolescência espacial urbana », Espaço e Economia [Online], 13 | 2018, posto online no dia 19 novembro 2018, consultado o 20 abril 2019. URL : http://journals.openedition.org/ espacoeconomia/4095; DOI : 10.4000/espacoeconomia.4095

Este documento foi criado de forma automática no dia 20 Abril 2019.

(c) NUPEE 


\section{Teoria da localização, teoria da renda fundiária urbana e o processo da obsolescência espacial urbana}

Theory of location, theory of urban ground rent and the process of urban spatial obsolescence

Théorie de l'emplacement, théorie de la rente foncière et le processus

d'obsolescence spatiale urbaine

Teoría de la localización, teoría de la renta de la tierra urbana y el proceso de la obsolescencia espacial urbana

André Vinicius Martinez Gonçalves

\section{Introdução}

1 Para a construção de uma teoria urbana capaz em nos explicar de maneira mais eficiente, entre outros fatores, a dinâmica fundiária na cidade e a forma como os mais diversos agentes atuam nessa realidade, Harvey (1980) chama a atenção para a necessidade de uma fusão conceitual entre a teoria da renda e a teoria da localização. Nesse sentido, tanto a renda fundiária e tudo o que ela comporta, bem como questão da localização, são elementos importantes no sentindo de compreensão de um processo desencadeado pela dinâmica fundiária urbana, no caso, a obsolescência espacial urbana ${ }^{1}$.

2 A noção de obsolescência como tema de investigação se contrapõe ao que se convencionou denominar de deterioração urbana nos estudos urbanos, que é impreciso e não responde ao processo que levam à decadência física, funcional e econômica dos ambientes construídos. O conceito de obsolescência espacial urbana refuta a noção de deterioração por entender que a problemática que se impõe nos ambientes construídos da cidade é de ordem sócio geográfica. 
O processo obsolescência espacial urbana está relacionada a incapacidade de determinada área da cidade garantir a manutenção de patamares elevados e satisfatórios da renda fundiária, lucros e das taxas de juros. Em outros termos, a obsolescência espacial em uma determinada área ocorre na medida em que os agentes econômicos - mercado imobiliário e proprietários de imóveis - não conseguem extrair taxas elevadas de renda, lucros e juros de suas propriedades, seja porque essas formas de remuneração do capital foram diminuídas e/ou amortizadas ao longo do tempo, seja pelo uso e desgaste das edificações e da infraestrutura, seja pela formação ou pelo redimensionamento de outras localidades na cidade, que atrai e polariza as ações e intervenções do Estado e de capitais de todas as ordens em detrimento das "antigas" e/ou "velhas" localidades.

O fator localização na cidade não pode ser dissociado da dinâmica de outro elemento, no caso, a terra-mercadoria, isto é, do mesmo modo em que não há espaço geográfico fora da lógica de reprodução do capital, não há localização fora da lógica da terra-mercadoria, bem como não há terra-mercadoria sem considerarmos a sua localização².

\section{As teorias da localização e da renda fundiária urbana como caminhos para a compreensão da obsolescência espacial urbana}

5 Para Seabra (1988), a renda fundiária constitui-se numa categoria teórica exploratória e explicativa das especificidades dos lugares inscritos espacialmente e socialmente. Diz ela em relação à renda fundiária: " $1^{2}$ - se define num conjunto de relações políticas e jurídicas; $2^{2}$ - como tal assume uma forma pertencente ao capital, no contexto da formação econômica social capitalista; $3^{\circ}$ - se constitui num volume de riqueza social com o qual se remunera a propriedade e $4^{\circ}$ - se constitui num elemento pertencente a este modo de produção sem que tenha a ver com a base fundamental do mesmo" (SEABRA, 1988, p.100).

O processo de produção e reprodução capitalista valoriza a terra na forma de propriedade, onde a renda que se obtém a partir das leis de reprodução é um meio de captação da mais valia da riqueza da sociedade. Como mercadoria, a terra comporta ao mesmo tempo, valor de uso e valor de troca, sendo a localização um dos valores de uso da terra-mercadoria. Porém, como se trata de mercadoria, a terra também comporta valor de troca, que se relaciona dialeticamente e se impõe sobre os valores de uso, sendo essa condição válida para a localização.

7 A localização é um dos componentes fundamentais no mercado de terras e, sobretudo, para a composição da renda fundiária urbana, que em última instância, é o fator basilar para a formação e composição do preço da terra. o preço é o elemento que vai garantir, no processo de produção das edificações de uso comercial, residencial e industrial, a extração da renda fundiária propriamente dita, os lucros e taxas de juros auferidos pelos agentes econômicos ligados direta e indiretamente ao mercado imobiliário.

Uma das principais referências em relação à teoria terra-localização é Flávio Villaça $(2001)^{3}$ a qual é base conceitual utilizada por arquitetos e urbanistas, e que em muitos casos, além de usarem o conceito de modo simplista, muitos desses são responsáveis e/ou integram quadros da Prefeitura Municipal de São Paulo, que desenvolvem projetos de intervenções urbanas, como por exemplo, as operações urbanas. Para efeito desse estudo, 
tomamos a forma e a linha de raciocínio ora desenvolvido por ele no sentindo de apresentar também o caminho proposto, por exemplo, por Harvey.

Villaça (2001) não coloca em lados opostos a teoria da renda e da localização, considera a existência da renda de monopólio, mas esta para ele não é significativa para a compreensão da dinâmica na formação dos preços da terra urbana. Em sua abordagem o elemento principal para a formação dos preços é a localização ou renda de localização como a predominante no espaço urbano.

10 De acordo com Villaça (2001), a terra urbana não se limita à condição de suporte de atividades econômicas e sociais que ocorrem na cidade. Ela, a terra urbana, teria a partir da produção social, um valor de uso, no caso sua capacidade de aglomerar, de combinar socialmente os meios de produção e os meios de reprodução de uma formação social. Ao mesmo tempo, esse valor de uso que reside em função das propriedades do espaço urbano estabelecem relações entre si, o que Villaça define como pontos ou localizações.

Villaça, situado em Queiróz Ribeiro (s/d. apud Villaça, 2001, p.. 74) afirma que:

[...] os mais diversos agentes econômicos que atuam na cidade, a terra urbana tem o papel de permitir o acesso aos efeitos úteis de aglomeração" onde "cada terreno particular permite maior ou menor valorização pelo acesso que sua localização propicia aos efeitos úteis de aglomeração.

13 Ainda pontua sob a perspectiva da localização como renda que a terra urbana também permite acesso aos efeitos úteis de aglomeração para a força de trabalho que se desloca de suas residências para os mais diversos pontos, como trabalho, escola, lazer etc. Para os defensores da teoria da localização, a terra interessa enquanto terra-localização, ou seja, enquanto meio de acesso a todo sistema urbano, a toda cidade, isto é, a acessibilidade nessa teoria é o valor de uso mais importante para a terra urbana.

Villaça (2001, p. 74-75), ao justificar o peso que a acessibilidade possui na cidade, a relaciona à quantidade de trabalho socialmente (produção social da cidade) necessário dispendido em sua produção e justificando da seguinte forma: "Quanto mais central for o terreno, mais trabalho existe despendido na produção dessa centralidade. Os terrenos da periferia tem menos trabalho social incorporado em sua produção do que nas áreas centrais". A localização como valor de uso seria resultado produzido pelo trabalho coletivo despendido da construção da cidade, assim quando se adquire o "ponto", isso significa pagar algo, não para o terreno, não pela edificação, não pelas suas instalações, mas pela localização.

15 No tocante à terra urbana, que nas palavras do mesmo autor seria um receptáculo de contínua acumulação de trabalho humano criador de valor, a tendência é que seu preço sempre aumente, havendo em um ou outro momento oscilações, mas sempre com tendência de aumento, condicionando esse preço sempre ao fator urbanização acessibilidade - localização. Assim, ele reconhece que toda terra tem algum grau de monopólio, porém na maior parte dos casos essa condição é pequena na determinação de seu preço e reforça que o preço da terra se dá pela sua produção e pelo seu valor, no caso o valor da localização, daí a denominação de terra-localização.

16 Seguindo a mesma linha de outros autores como Rodrigues (1988), Harvey (1980) e Lefebvre (2001), Villaça (2001) considera que as cidades são forças produtivas e, como tal apresentam uma lógica, uma lei e não uma desordem, tanto que potencializam a produtividade do trabalho social. Não fosse essa condição das cidades em não apresentarem esse caráter de força coletiva, essas não teriam o desenvolvimento que 
tiveram sob o capitalismo, assevera o autor. Da mesma maneira, ainda analisa a importância dos sistemas de circulação, no caso em específico, as estradas, para as aglomerações urbanas nos seguintes teremos:

17 Marx deixa clara a existência de dois excedentes: um oriundo das forças produtivas que potencializam o trabalho individual e outro decorrente das chamadas "causas gerais da elevação da produtividade do trabalho" ou "força produtiva social do trabalho" A questão é assim colocada por ele referindo-se à construção de estradas, mas propomos a transferência dos raciocínio para as aglomerações representadas pelas cidades. “Concentração é sempre acréscimo da parcela da capacidade de trabalho que casa indivíduo pode empregar na construção de estradas, além de seu trabalho particular, mas não é somente acréscimo, A unificação de suas forças aumenta suas forças de produção; entretanto isso não significa de maneira alguma o mesmo que dizer que todos numericamente somados, possuiriam a mesma capacidade de trabalho que teriam se não trabalhassem em conjunto, portanto, se à soma de suas capacidades de trabalho não fosse acrescentado o excedente existente somente no e através de seu trabalho unificado e combinado" (Villaça: 2001, p. 77).

18 Esse valor de uso oriundo da força produtiva social do trabalho, da aglomeração da cidade consiste no valor de uso das localizações. Villaça considera a existência de outros valores de uso da terra, como por exemplo, a infraestrutura, mas insiste na tese que o fator localização é o elemento fundamental para o preço da terra.

19 Considera ainda que o valor de uso dos edifícios, ruas, infraestrutura se transferem para o ponto, ou seja, para o valor de uso localização. Nesse sentido, a localização (pura) funcionaria como um grande receptáculo de outros valores de uso inerentes à terra urbana, sendo ela, o valor de uso primordial na construção de preços das terras urbanas. Da mesma maneira, defende que os agentes econômicos que atuam no setor imobiliário das cidades se governam pelas localizações das terras, as centralidades ou não que elas ocupam, permitindo desse modo um maior ou menor grau de conexão com outros pontos da cidade, isto é, haveria aqui o que ele denomina de diferenciais de localização que são captados pelos terrenos, daí a diferenciação nos preços entre terrenos localizados em área centrais e terrenos situados em áreas da periferia.

20 Na contramão do que defende, por exemplo, Topalov (1979), Villaça (2001, p. 79) nega a existência da renda diferencial no urbano. Diz ele:

21 É um equívoco comparar a fertilidade da terra agrícola - "um dom gratuito da natureza" com a localização, fruto de trabalho socialmente necessário. Aquilo que se chamaria de renda diferencial no espaço urbano é na verdade um diferencial de valor. Os terrenos têm preços diferentes porque têm valores diferentes, e não porque produzem rendas diferentes.

Para corroborar com sua tese, apega-se a ideia do terreno vago para demonstrar sob seu ponto de vista a distinção entre renda e valor da localização. Para tanto considera que sua [...] valorização é acréscimo de valor resultante da produção da cidade e na cidade, logo o terreno vago não gera renda diferencial. Seu valor, seu preço é determinado pela localização, isto é, pela terra-localização que é a expressão monetária desse valor (Villaça: 2001, p. 79).

Para ele as mudanças de uso ou transformações urbanas não geram rendas diferenciais, mas sim atualizações e reajustes no preço da terra. Um dos reajustes considerados por Villaça é a demolição de edificações, pois é a através dessa ação que o valor obstruído por 
uma dada edificação liberará esse valor, possibilitando a atualização do preço do terreno "condizente com o seu valor atual".

A renda fundiária na realidade urbana considerada por Villaça é a renda absoluta, o que ele define como uma espécie de renda de monopólio, diz ele:

Esta, em alguns - a minoria -, pode ser enorme e em outros - a maioria -, que pode ser pequena. Em qualquer caso, contudo, afetará o preço do terreno, mas o elemento determinante no preço será dado pelas transformações dos pontos: seus atributos, valores e preços, seus usos, os quais decorrem, em última instância, da melhoria de acessibilidade (Villaça: 2001, p. 79).

27 Em suma, para Villaça, a localização como valor de uso é a definidora, o elemento ou fator principal do preço da terra urbana. Não se nega aqui a relevância do ponto de vista conceitual e reflexivo sobre a teoria terra-localização. Trata-se de um modelo muito bem elaborado o qual nos conduz a refletir e dialogar com outros modelos e conceitos para tratar da problemática da obsolescência espacial urbana, porém, para os objetivos de uma análise geográfica da qual nos propomos, ele nos permite responder somente um lado da questão que envolve o processo, no caso a dimensão da localização.

Como dissemos anteriormente, Villaça argumenta que pessoas jurídicas e físicas adquirem via compra ou locação da terra, o ponto, isto é, se adquire a localização. A localização é utilidade da terra, valor de uso. Entretanto, para obter uma localização, essa condição passa necessariamente por quem detém o ponto, ou seja, o proprietário, que via à condição da propriedade privada da terra, detém o monopólio desse ponto.

Em outros termos, esse ponto, no caso a propriedade privada situada em uma determinada localização não é outra coisa que não valor de troca para o seu proprietário, ou seja, para que qualquer um possa usufruir do valor de uso desse ponto e de sua localização deve-se antes pagar um preço (compra ou aluguel), sendo essa expressão monetária do valor de troca.

Em função dessa especificidade da terra-mercadoria, ou seja, o monopólio exercido por um determinado agente, é que outros agentes e sujeitos conseguem, caso o primeiro esteja disposto, a vender ou locar esse ponto. Na medida em que isso ocorre, esse ponto, esse valor de uso, permite ao comprador ou ao locatório o acesso a outros valores de uso situados tanta na área da qual a localização se situa como em outras áreas da cidade.

31 Por outro lado, para que os agentes tenham acesso aos valores de uso de todas as ordens, significa que eles precisam na compra e na locação da terra-mercadoria, pagar o preço a terceiros, os que detêm, via o monopólio da terra, o valor de troca dessa mercadoria.

32 A localização como valor de uso é produzida, não isolada da totalidade da cidade, pelo trabalho de toda sociedade, entretanto, via a socialização capitalista do espaço, esse atributo, essa qualidade da terra, ao mesmo tempo em que é usada coletivamente em maior ou menor grau por todos é incorporado também na composição do preço da terra pelos que exercem o monopólio dessa mercadoria.

33 Além disso, os proprietários de terra e outros agentes que atuam no mercado e que usam a terra "como fundação, como um lugar e um espaço que proporciona uma base de operações - o espaço é requerido como um elemento de toda produção e atividade humana" (Harvey: 2013, p. 436), de toda atividade econômica, na medida em que a força de trabalho circula entre as localizações e capta uma fração dos salários que serão convertidos em renda fundiária, lucro e juros. 

capitalista de terras somente tem relevância como valor de uso na medida em que ela dialeticamente se relaciona com o valor de troca. Isso significa dizer que uma localização produzida, reinventada ou resgatada só se torna espacialmente relevante sob a perspectiva do mercado imobiliário na medida em que ela atende as necessidades e imposições dos agentes que detém para si o valor de troca da terra-mercadoria. Sendo assim, essas localizações que se materializam na cidade, via o trabalho socialmente necessário, ao serem aprisionadas sob a lógica do valor de troca dos que monopolizam a terra, traduz para esses a possibilidade no presente e no futuro de obterem ou de renovarem o potencial de renda fundiária a ser auferida, além dos lucros e juros decorrentes das operações do mercado imobiliário.

mos considerar que todas as localizações acabam em menor ou maior grau ao longo do tempo sendo aprisionadas sob a lógica do valor de troca, e é esse último, de acordo com os interesses dos agentes que o detém, é que vão potencializar também em maior ou menor grau o peso da localização na composição dos preços da terra urbana, bem como a importância da localização no âmbito do uso realizado coletivamente.

Por exemplo, uma gleba de terra desnuda tem o seu preço gradualmente corrigido e elevado para cima pela sua localização, mas ela sozinha seria insuficiente para alçar esse preço, para tanto se faz necessário os investimentos em infraestrutura realizados pelo Estado e construção de edificações de todas as ordens e usos públicos e privados no entorno da localização e na localização. detrimento de outras e novas localizações o preço da gleba, mesmo de modo moderado, tende a ter seu preço corrigido sempre para cima. Nesse sentindo, consideramos que Villaça não dá conta de explicar todo o processo, pois em sua ótica, o preço de um terreno vago ocorre mediante somente a valorização da localização.

Ora se uma localização "desvaloriza", perde valor ou tem o seu valor diminuído em função de outras localizações e/ou em função de outros fatores inerentes à própria localização, como explicar a elevação de preços desse terreno vago, mesmo que isso ocorra abaixo da média do mercado?

39 A mesma lógica pode ser aplicada para lotes e áreas edificadas, os quais se por um lado podem ter seus conjuntos físicos e econômicos desvalorizados em função dos fatores que na sua totalidade desencadeiam a obsolescência espacial por outro, mesmo que a localização tenha tido reduzido seu valor frente a outros localizações, o preço desses lotes e áreas são constantemente alterados, porém nunca para baixo.

40 Como bem salienta Rodrigues $\left(1988\right.$, p.82) “[...] mesmo quando as edificações se deterioram ${ }^{4}[. .]$. é possível comprar-se um terreno com edificação e destruí-la, pois é, muitas vezes, um terreno caro sobre uma edificação barata, - pagou-se pelo terreno que nunca se estraga".

41 Marx $(1996,2001)$ considera dois estágios no processo de transformação de valores em preços de produção. No primeiro estágio, ocorre uma abstração relativa ao valor dos meios de produção de modo a dar valimento que o valor é produzido apenas pelo trabalho. Em outros termos na medida em que ocorre maior quantidade de trabalho em um dado processo produtivo maior será a quantidade de mais-valia produzida. No momento da distribuição da mais-valia, conforme o tamanho de cada capital, forma preços diferentes dos valores. 

civil voltada ao setor imobiliário assinalado, ou seja, esse setor por um lado possui baixa composição orgânica do capital e por outro relativamente emprega mais trabalhadores o que acaba por gerar um maior montante de mais valia, o que potencializa nesse setor e seus agentes envolvidos mais obtenção de lucros, renda e juros, considerando que esses são resultados diretos da mais valia.

No segundo estágio, Marx analisa a economia ao nível dos preços de produção, ou seja, todas as mercadorias são vendidas aos seus preços, e os preços dos insumos são considerados, além dessa condição destaca que a transformação permite uma maior determinação na forma do trabalho social, explicando dessa forma a distribuição do trabalho e da mais-valia através da economia.

Em uma dimensão abstrata, o valor de uma mercadoria é diretamente ligado a uma relação social de produção e em termos quantitativos o valor é o tempo de trabalho socialmente necessário para reproduzir cada tipo de mercadoria, conforme explicitado por Marx (1996; 2001). O valor também deve ser visto como a expressão monetária desse tempo de trabalho socialmente necessário em termos de preço direto, preço de produção, ou preço de mercado.

Na realidade espacial urbana, essa condição torna-se mais complexa, ou seja, no preço de mercado, quais são os elementos considerados pelo setor imobiliário para quantificar o valor de um dado ambiente urbano construído composto por um conjunto de objetos atuais e objetos pretéritos, ou em outros termos um ambiente constituído por uma sobreposição de produções e usos dados ao longo de um tempo?

Uma coisa é o preço inicial determinado na produção direta e atual de um imóvel ou do preço de um terreno desnudo, a outra é quando esses preços são mensurados a partir da totalidade do processo, ou seja, a relação entre o preço da mercadoria individual, por exemplo, uma moderna edificação e o valor do ambiente e/ ou localização da qual se situa essa mercadoria.

De modo inverso, consideramos como o valor e/ou preço de um antigo imóvel, ou em termos espaciais, como determinadas áreas se comportam diante de um novo ambiente que gradualmente tende a difundir uma renovação do uso do solo? Utilizar somente o conceito de terra-localização é insuficiente para se compreender essas questões.

Jean Lojkine (1979) indaga: Existe uma renda fundiária urbana ${ }^{5}$ ? Entendemos que é possível continuarmos a pensar, adotar e aceitar a existência da renda fundiária urbana, visto que essa categoria analítica, diante das cortinas de fumaça conceituais construídas pelos modelos neoclássicos e neoliberais da economia, que se debruçam sobre a realidade urbana, ocultam de modo sofisticado os reais processos desencadeados pelos agentes que produzem o urbano, em especial, o Estado nas suas mais diversas instâncias e o Capital vinculado ao setor imobiliário.

49 Ignorada de modo deliberado ou intencional, fato é que a renda urbana fundiária, como contraponto, como categoria crítica de análise e reflexão da realidade urbana é de fundamental importância para a compreensão dos processos que se impõe na realidade da cidade, sendo um deles, a obsolescência espacial urbana.

De acordo com Harvey (1980, p.150), o conceito de rentabilidade ocupa posição crítica nas teorias do uso do solo urbano. Em suas palavras: 
51 Muitos teóricos da localização compreendem que se faz necessário uma fusão entre as teorias da renda com a teoria da localização [...]. A renda age como artifício racional que seleciona usos do solo em localização, crê-se por via de lances competitivos.

Ainda em relação à renda, Harvey (1990, p. 340) nos diz que:

53 A renda é o conceito teórico por meio do qual a economia política [...] tradicionalmente enfrenta o problema de organização espacial. A renda [...] fornece uma base para várias formas de controle social sobre a organização espacial e do desenvolvimento do capitalismo.

Um dos aspectos negativos relativo ao conceito de renda é a forma como esta surge nesta obra de Harvey de modo inocente na teoria do solo urbano, acobertando problemas de ordem mais sérios ligados a sua interpretação. Para Harvey (1990), o ponto crucial do solo urbano está circunscrito à complexidade da oferta e demanda do solo urbano em suas diferentes parcelas. De um lado, oferta e demanda estão relacionadas de maneiras significativas, mas de outro, pobremente compreendidas. Ele propõe retomar a riqueza da economia política para esclarecer a natureza da renda e ao mesmo tempo se contrapor a ocultação feita pela empresa neoclássica, em especial aspectos técnicos e éticos que se ligam à renda, e como esta de fato age no mercado do solo urbano ${ }^{6}$.

Partindo do princípio que a propriedade do solo está baseada no monopólio por parte de algumas pessoas em detrimento da exclusão de outras, Harvey (1990), ao refletir a respeito do conceito de renda em o Capital e em Teorias da Mais-Valia, assevera que “ Marx se propõe descobrir as diferenças que de outro modo poderiam escapar à averiguação". São definidas três espécies básicas de renda, que tipicamente surgem no modo de produção capitalista: i) Renda de monopólio; ii) Renda diferencial e iii) Renda absoluta.

56 A análise do uso do solo urbano ou da terra urbana permite múltiplas possibilidades para a compreensão de processos que ocorrem em qualquer cidade do mundo. Conforme já explicitado, trata-se a terra urbana de uma mercadoria especial dada as suas condições diferenciais em relação a outras mercadorias.

57 Na cidade, os elementos naturais que possuem relação com a renda fundiária são as condições hidrográficas, vegetacionais, geológicas, as condições climáticas e as feições do relevo presentes em uma determinada área e, quando cooptadas pelo mercado de terras, podem se tornar amenidades geográficas no sentido de impulsionar uma renda fundiária mais elevada, logo preços de terrenos e imóveis mais elevados.

O solo agrícola e a terra urbana, no tocante à formação das rendas fundiárias, se aproximam quando se trata da renda absoluta, ou seja, o monopólio da terra via a propriedade privada. Esse monopólio garante a todos os proprietários um lucro extraordinário não em função de amenidades $\mathrm{x}$, $\mathrm{y}$ ou $\mathrm{z}$, nem em função do trabalho excedente dos trabalhadores em uma determinada propriedade ou empreendimento, mas sim, em função da fração da massa de mais-valia global dos trabalhadores.

Outro tipo de renda da terra urbana é a diferencial analisada entre outros por Harvey $(1980,2013)$ e Rodrigues (1988), também chamada de renda de localização. Esse tipo de renda é produzido a partir de localizações e áreas privilegiadas determinadas pelo mercado em que os consumidores estão dispostos a pagar uma renda de monopólio para ali se localizarem, seja em função de uma condição de status individual ou de necessidades relativas às exigências de uma determinada atividade econômica, em especial, aquelas sintonizadas com as necessidades da economia globalizada. 
60 Dada às particularidades da cidade, o conceito da terra urbana é o mais adequado para a compreensão de parte do processo da obsolescência espacial urbana. 0 termo, além de marcar as diferenciações na formação de rendas fundiárias, permite compreender melhor a forma como os diversos agentes produtores da cidade atuam, em especial, aqueles que compõem o setor da indústria do imobiliário.

61 Por terra urbana compreende-se o que temos acima e abaixo da superfície na cidade. Abaixo, ou aquilo que se define como subsolo urbano, temos toda uma infraestrutura marcada por galerias de captação pluvial e fluvial, tubulações de redes de água, esgoto e gás e cabeamento de todas as ordens tais como energia elétrica, telefonia, fibra ótica. Entretanto, há de salientar que em São Paulo especificamente esses elementos não se fazem presentes na totalidade da cidade, bem como muitos dos que se fazem muitas vezes pelo tempo de uso e das suas condições técnicas são precários, ou seja, devem também ser considerados como fatores de obsolescência.

62 Acima, no caso o solo, com base para um conjunto complexo e um conjunto simples de valores de uso, temos as pavimentações, ruas, avenidas, ruelas, calçadas, postes de iluminação, telefonia e internet, jardins e parques, sistemas de drenagem, pontes, viadutos entre outros, bem como temos edificações de todas as ordens, além de terrenos vazios e ociosos.

Em que pese essa ligeira diferença entre o uso das terminologias "solo e terra urbana", o fato é nosso entendimento sobre a relevância da renda fundiária aplicada nos estudos urbanos vai ao mesmo sentido daquele proposto por Harvey (1980, 2005, 2013), Lojkine $(1979,1997)$ e Rodrigues $(1988)$, ou seja, que a dinâmica da realidade urbana das cidades capitalistas e todos os processos pertinentes a sua realidade fundiária passa necessariamente pela compreensão da renda da terra.

64 A renda fundiária, uma fração da mais-valia ou mais precisamente, componente particular e específico da mais-valia se trata de um valor extraordinário apropriado sob a lógica do mercado de terras aos que detém a propriedade privada dessa mercadoria ou nos termos precisos colocados por Oliveira (2007, p.43):

65 A renda da terra é uma categoria especial na Economia Política, porque ela é um lucro extraordinário, suplementar, permanente, que ocorre tanto no campo como na cidade. $O$ lucro extraordinário é a fração apropriada pelo capitalista acima do lucro médio [...]. Como ela é um lucro extraordinário permanente, ela é, portanto, produto do trabalho excedente [...] o trabalho excedente é a parcela do processo de trabalho que o trabalhador dá ao capitalista, além do trabalho necessário para adquirir os meios necessários à sua subsistência.

Esse lucro extraordinário, de acordo com Oliveira, trata-se de renda capitalizada, pois, na medida em que os investidores e capitalistas compram a terra estão "convertendo o seu capital-dinheiro em renda capitalizada da terra, renda antecipada, ou seja, estão adquirindo o direito de extrair renda, mesmo naqueles lugares onde aparentemente ela pode não existir" (OLIVEIRA, 2007, p. 63). Já na cidade, a renda assume uma forma abstrata, ou seja, "a renda não se apresenta mais como um produto do solo como ocorre no campo, ela aparece como nada mais que o juro de um capital investido" (BOTELHO, 2008, p. 26).

67 Além disso, "a renda da terra é determinada pelo uso socialmente estabelecido na organização da produção e circulação, paga ao proprietário, consequência do valor de 
troca, muitas vezes antecedida à determinação do uso por ações de especulação e escassez de localizações" (HARVEY, 1980, p.154).

Harvey (1980) ainda afirma que a renda não pode ser entendida sem se fazer citação ao pagamento que ocorre em circunstâncias sociais, bem como nos chama atenção para a realidade de que o espaço urbano não é absoluto, relacional ou relativo, mas são todos os três simultaneamente, dependendo das circunstâncias do tempo.

A análise da renda fundiária nos possibilita confrontar e elucidar o modo como os agentes ligados ao setor imobiliário atua na cidade, pois conforme já dissemos, apesar de mecanismos e fórmulas bem elaborados e adotados por esse segmento em relação aos preços praticados no processo de compra e venda de imóveis e terrenos, esses mais ocultam do que clarificam.

Fato é que os próprios agentes que atuam no ramo imobiliário não negam que o preço de terras no urbano é de ordem complexa, e mais complexa e oculta se torna quando fatores como a renda, lucro e juros projetados e obtidos pelas empresas que atuam no mercado é de pouco conhecimento, em especial, para aqueles que adquirem os valores de usos que as edificações proporcionam.

71 A partir de um rápido exemplo que vai do custo de produção ao preço final de imóvel, vamos considerar inicialmente o custo de construção de uma casa tendo como parâmetro os dados do SINAPI (Sistema Nacional de Pesquisa de Custos e Índices da Construção Civil do IBGE).

Em novembro de 2012, o valor médio do $\mathrm{m}^{2}$ para a construção civil em São Paulo era de $\mathrm{R} \$$ 921,53. Considerando diferentes tipos de padrão construtivo (alto, normal, baixo e mínimo) definidos pelo $\operatorname{IBGE}^{7}$ (2012), além do tipo do projeto, ou seja, uma casa popular, casa residencial normal, prédio residencial, prédio comercial e em cada um deles com várias particularizações, temos os seguintes custos (Tabela 3.1):

\subsection{Tabela Custos de Construção / São Paulo (2012)}

\begin{tabular}{|l|l|l|}
\hline Alto & Normal & Baixo \\
\hline $\mathrm{R} \$ 1.336,09$ por $\mathrm{m}^{2}$ & $\mathrm{R} \$ 962,49$ por $\mathrm{m}^{2}$ & $\mathrm{R} \$ 679,81 \mathrm{~m}^{2}$ \\
\hline
\end{tabular}

\section{Civil do IBGE (2012)}

Como exemplo, um projeto de Casa residencial padrão normal com $70 \mathrm{~m}^{2}$, contendo um pavimento, varanda, sala, três quartos, circulação, banheiro, lavabo, cozinha, área de serviço, quarto e WC de empregada. O preço pago pelo terreno onde será construída a casa foi de $\mathrm{R} \$ 250.000$ e o preço final dessa casa padrão normal situada em um dado lugar foi colocada à venda por $\mathrm{R} \$ 400.000$, ou seja, 5.714 reais o preço do $\mathrm{m}^{2}$.

Considerando o custo de produção do $\mathrm{m}^{2}$, a casa saiu por aproximadamente $\mathrm{R} \$ 67.500$. Se o custo de comercialização desse imóvel foi de $5 \%$, ou seja, $\mathrm{R} \$ 20.000$ sobre o preço final do imóvel, a margem de lucro do empreendedor, gira conforme o mercado imobiliário entre $10 \%$ e $20 \%$ do preço pago no terreno. Se considerarmos nesse exemplo uma margem de $15 \%$ isso equivale a $\mathrm{R} \$ 30.000$

Pela matemática simples temos: $R \$ 250.000$ do terreno + $R \$ 67.500$ do custo de produção + $\mathrm{R} \$ 20.000$ da comercialização + $\mathrm{R} \$ 37.500$ do lucro do empreendedor. $\mathrm{O}$ resultado final é 
de: $\mathrm{R} \$ 375.000$. Entretanto, a casa foi vendida por $\mathrm{R} \$ 400.000$, ou seja, há ai uma diferença de $\mathrm{R} \$ 25.000$.

O fato é que o empreendedor, ao pagar $\mathrm{R} \$ 250.000$, já projetava o montante de $\mathrm{R} \$ 400.000$ como preço final, e a sua alegação é que se trata de uma nova casa e essa está inserida em uma localização satisfatória que dá acesso a uma gama de prestações de serviços, comércio, facilidade de circulação e ligação com outras regiões, acesso satisfatório ao transporte público entre outras amenidades.

Esse breve exercício contempla de modo mínimo a realidade operacional do mercado. Mínimo por que em geral o lucro extraordinário aqui exemplificado tende sempre a ser maior. A questão é que o que vende a casa e ou terreno (pessoa física) não tem de fato a dimensão do preço final a ser praticado pelo empreendedor (pessoa jurídica).

Se a casa for financiada pelo setor bancário o empréstimo do valor solicitado será acrescido de juros e será pago ao longo do tempo, fazendo com que a instituição bancária obtenha ganhos a partir do preço do imóvel que fora determinado pela renda futura projetada pelo empreendedor.

Rodrigues (1988, p75.) clarifica essa questão da seguinte forma:

De modo geral, esta mercadoria "sui generis" tem seu preço determinado não pela produção, mas pela taxa média de lucro de aplicação dos capitais. O trabalhador, ao adquirir um terreno para construir uma casa, ou uma casa pronta, estará assim remunerando ao capital, no preço da terra, a taxa média de lucro do capital em geral. A remuneração do capital empregado na aquisição estará garantida e embutida na mercadoria terra urbana. A terra urbana, espécie de mercadoria, tem um preço que aparece como ditado pelo mercado, quando originalmente foi definido como monopólio de propriedade e posteriormente é constantemente redefinido pela produção social da cidade. [...] No caso da mercadoria terra não há preço de produção da terra nua, o preço é redefinido pela produção social da cidade, porém aparece como se fosse definido pelo mercado. Mas o que é definido pelo mercado é a renda.

A questão é que cada vez mais na realidade do mercado imobiliário os diferentes agentes atuantes se fundem, até mesmo porque, e isso é demonstrado por Fix (2007), raramente salvo exceções, o empreendedor consegue produzir sozinho um empreendimento. Além disso, também estão envolvidos os setores bancário e financeiro, ou seja, há uma tendência de cada vez mais a atuar nas duas pontas, isto é, financiando a produção da edificação e financiando a compra do produto final.

\section{Considerações finais}

84 A exposição sobre a problemática da renda fundiária urbana e da teoria localização para o nosso propósito possui relevância quando refletimos outro processo, no caso, a obsolescência espacial urbana, que decorre da dinâmica das rendas fundiárias que ocorre em um dado lugar.

Uma gama de mercadorias móveis é consumida no cotidiano. Para o sistema capitalista, hoje controlado pela esfera bancária e financeira, é fundamental que elas sejam destruídas o mais rápido possível e a partir disso o consumo se torne exponencial. Essa destruição não se dá somente pelo uso de uma mercadoria por um determinado tempo, mas também pelo constante lançamento de novas mercadorias que em função de seus 
apelos oriundos tecnológicos e do marketing colocam de modo prematuro e intencional um conjunto significativo de objetos na condição de obsoletos.

Na realidade urbana, na produção imobiliária da cidade, não diferentemente do que ocorre na esfera industrial, bancária e financeira, para que o mercado imobiliário seja continuamente remunerado através da renda, lucro e juros, a produção também não pode cessar, seja na ampliação de novas áreas, seja na "renovação" que por convenção são chamadas de áreas degradadas.

No entanto, o setor imobiliário na medida em que atua sob o espaço da cidade esbarra em inúmeros obstáculos os quais ele precisa superar. Dizer como Milton Santos (1990) que cidades como São Paulo nunca envelhecem deve ser tomado com algo relativo e com cuidado, pois áreas e setores dos quais o capital imobiliário não possui interesse ou não consegue atuar dentro da sua lógica de reprodução objetivando conforme temos insistido na busca pela renda, lucro e juros, tais áreas e setores entram em processo de obsolescência espacial, sendo que o resultado dessa obsolescência é expresso na defasagem técnica das edificações e de suas localizações.

Harvey (1980, p.137) salienta que, "a apropriação da renda é aquela forma econômica na qual a propriedade do solo se realiza". A propriedade do solo baseada no monopólio da propriedade além do fator renda, entre outros, também garante aos proprietários dentro dos limites estabelecidos pela legislação urbana ${ }^{8}$ determinar o uso que será dado à suas propriedades, bem como lhe possibilita realizar de acordo com os seus interesses alterações nas formas, estruturas e funções que suas propriedades desempenham ou podem vir a desempenhar. $\mathrm{O}$ monopólio da terra ainda permite aos proprietários uma atuação na dinâmica do mercado imobiliário cedendo ou não, se articulando ou não junto às demandas dos agentes econômicos desse setor, se articulando ou não com os mais diversos agentes produtores do espaço urbano, dentro das normas do Estado de direito, mesmo que elas sejam sempre alteradas.

Sob essa perspectiva, entendemos que nesse caminho seja possível compreender melhor os motivos que levam a diferenciação espacial em uma cidade como São Paulo. Entendemos que a forma como os agentes econômicos - o que inclui os rentistas propriamente ditos, além do Estado -, ao agirem na produção do espaço urbano, determinando o que, quanto, onde e como investir, desencadeiam as diferenciações espaciais, gerando no processo de modernização espacial de certas áreas da cidade o seu contrário, no caso, a obsolescência espacial, o que não deixa de ser uma forma de segregação espacial.

\section{BIBLIOGRAFIA}

BOTELHO, Adriano. A renda fundiária urbana: uma categoria de análise ainda válida. GEOgraphia, Vol. 10, No 19, pp. 24-45, 2008.

BRASIL. Instituto Brasileiro de Geografia e Estatística. SINAPI - Sistema Nacional de Pesquisa de Custos e Índices da Construção Civil do IBGE, 2012. 
FIX, Mariana. São Paulo cidade global: Fundamentos financeiros de uma miragem. São Paulo: Boitempo, 192p, 2007.

GONÇALVES, André Vinícius Martinez. Obsolescência Espacial Urbana: O Ambiente Urbano de Santana em São Paulo - SP. Tese de Doutorado apresentada ao IGEO/IGE da UNICAMP, 2015.

HARVEY, David. Os limites do capital. São Paulo: Boitempo, 592p, 2013.

HARVEY, David. A produção capitalista do espaço. São Paulo, Annablume, 251p, 2005.

HARVEY, David. Los límites del capitalismo y la teoría marxista. México: Fundo de Cultura Económica, 469p, 1990.

HARVEY, David. A Justiça Social e a Cidade. São Paulo: HUCITEC, 291p, 1980.

LEFEBVRE, Henri. O direito à cidade. São Paulo: Centauro, $2^{\mathrm{a}}$ ed, 141p, 2001.

LOJKINE, Jean. O estado capitalista e a questão urbana. São Paulo: Martins Fontes, 360p, 1997.

LOJKINE, Jean. Existe uma renda fundiária urbana? In: Marxismo e Urbanismo capitalista. São Paulo: Livraria Editora Ciências Humanas, pp. 81-91, 1979.

MARX, Karl. o Capital, Livro I. Rio de Janeiro: Civilização Brasileira, 571p, 2006.

MARX, Karl. O capital - crítica da economia política / vol. I - Livro primeiro: O processo de produção do capital. São Paulo: Coleção “Os Economistas”, Editora Nova Cultural Ltda, 473p, 1996.

OLIVEIRA, Ariovaldo Umbelino de. Modo de produção capitalista, agricultura e reforma agrária. São Paulo: FFLCH/Labur Edições, 185p, 2007

RODRIGUES, Arlete Moysés. Na procura do lugar o encontro da identidade - Um estudo do processo de ocupação de terras: Osasco. Tese de Doutorado apresentada à Faculdade de Filosofia, Letras e Ciências Humanas - Departamento de Geografia da Universidade de São Paulo, 1988.

SANTOS, Milton. Por uma economia política da cidade. São Paulo: Hucitec/Educ, 1994.

SANTOS, Milton. Metrópole corporativa e fragmentada - O caso de São Paulo. São Paulo: Nobel, 116p, 1990.

SEABRA, Odette Carvalho de Lima. Pensando o processo de valorização e a geografia. Boletim Paulista de Geografia /AGB, ํㅡ6, 1ํㅗ․, pem. 94-107, 1988.

TOPALOV, Christian. Análise do ciclo de reprodução do capital investido na produção da indústria da construção civil. In: Marxismo e Urbanismo capitalista. São Paulo: Livraria Editora Ciências Humanas, pp. 53-80, 1979.

VILLAÇA, Flávio. Espaço intra-urbano no Brasil. São Paulo: Nobel/FAPESP, 376p, 2001.

\section{NOTAS}

1. O processo da obsolescência espacial urbana é amplamente discutido em nossa tese de doutoramento, Gonçalves (2015).

2. A terra em si mesma não possui a propriedade de ser mercadoria. Isso só ocorre mediante a formação do mercado de terras. Ao se tornar mercadoria, equivalente de trabalho ou a terra como trabalho, diz-se que se trata de uma mercadoria especial, pois ela possui características peculiares que nenhuma outra mercadoria tem. Sobre as particularidades e peculiaridades da terra-mercadoria consultar Harvey (1980, p. 135-6)

3. VILLAÇA, Flávio. Espaço intra-urbano no Brasil. São Paulo: Nobel/FAPESP, 2001. 
4. A deterioração dos ambientes construídos é em nosso entendimento um dos recortes de uma totalidade maior, no caso a obsolescência espacial urbana.

5. Livre tradução de: "Y a-t-il une rente foncière urbaine"?

6. Também a respeito da riqueza da Economia Política nos estudos e pesquisas geográficas consultar Santos (1994).

7. SINAPI - Sistema Nacional de Pesquisa de Custos e Índices da Construção Civil do IBGE

8. Porém, nem sempre isso ocorre na cidade de São Paulo, muitos são os proprietários fundiários de todas as ordens que através de múltiplos mecanismos burlam a legislação.

\section{RESUMOS}

Este artigo coloca em discussão as teorias da localização e da renda fundiária urbana no sentido de se compreender parte de um elemento da dinâmica fundiária na cidade capitalista, no caso o processo da obsolescência espacial urbana, que se contrapõe ao que se convencionou denominar de deterioração urbana, que é impreciso e não responde aos fatores que levam a decadência física, funcional e econômica dos ambientes construídos.

This article questions theories of location and urban ground rent, to understand elements of land dynamics in the capitalist city, in this case the process of urban spatial obsolescence opposes what is usually called urban decay which is imprecise and doesn't suit the process that leads to physical functional and economic decay of a built-up area.

Cet article met en question des théories de l'emplacement et de la rente foncière urbaine afin de comprendre une partie d'un élément de la dynamique foncière dans la ville capitaliste, dans ce cas le processus d'obsolescence spatiale urbaine, qui contraste avec ce convenu nommer la détérioration urbaine, qui est imprécise et ne répond pas aux facteurs qui conduisent à la décadence physique, fonctionnelle et économique des environnements construits.

Este artículo se encuentra dentro de las áreas de la ciudadanía y de la ciudad. No se trata de un proceso de obsolescencia de la ciudad, sino también de la ciudadanía capitalista. ¿Qué es lo impreciso y lo que no responde? Aos fatores que levan una decadencia física, funcional y económica dos ambientes construidos.

\section{ÍNDICE}

Mots-clés: Théorie de l'emplacement, rente foncière urbaine, obsolescence spatiale urbaine, ville capitaliste, environnements construits.

Palavras-chave: Teoria da localização, renda fundiária urbana, obsolescência espacial urbana, cidade capitalista, ambiente construído.

Palabras claves: Teoría de la localización, fondo urbano, obsolescencia espacial urbana, capitalista, ambiente construido.

Keywords: Location theory, urban ground rent, urban spatial obsolescence, capitalist city, built environment. 


\section{AUTOR}

\section{ANDRÉ VINICIUS MARTINEZ GONÇALVES}

Doutor em Geografia pela Universidade Estadual de Campinas (UNICAMP) e Mestre em Geografia pela Universidade de São Paulo (USP). Professor do Instituto Federal de Educação, Ciência e Tecnologia de Goiás. Integrante do grupo de pesquisa Problemática Urbana e Ambiental da UNICAMP e do grupo de pesquisa Uso e Conservação de Recursos Naturais da UEMG/Frutal MG.Email : reclusgeo@hotmail.com. 